\title{
APRECIAÇÃO DUBITATIVA DO REALISMO E SEU IMPACTO SOBRE A COSMOLOGIA CRISTÃ REALISTA
}

Carlos Eduardo Pereira Oliveira*

Resumo: O presente artigo deseja expor a apreciação dubitativa do realismo na Primeira Meditação, no intuito de mostrar o impacto dessa ação cartesiana sobre a doutrina da creatio ex nihilo, consolidada filosoficamente por Tomás de Aquino como autêntica cosmologia cristã, em substituição à cosmologia pagã erguida sobre o princípio ex nihilo nihil fit. Faremos, primeiramente, uma breve exposição dos fundamentos realistas que embasam as provas da criação elaboradas pelo Aquinate. Em seguida, apresentaremos como a submissão do realismo ao método cartesiano da dúvida acarreta o inevitável desmoronamento do edifício cosmológico cristão.

Palavras-chave. Tomás de Aquino. Realismo. Cosmologia. Descartes. Dúvida.

\section{Introdução}

Há já algum tempo frequentando as Meditações, fomos persuadidos de que nelas existe uma teoria cartesiana da criação capaz de fundamentar a polêmica teoria da livre criação das verdades eternas, de cuja junção provavelmente resultaria uma cosmologia cartesiana que marca o início da cosmologia moderna.

O presente artigo, no entanto, tem outro propósito que apresentar a teoria cartesiana da criação, qual seja descobrir o que motivou Descartes a elaborar uma teoria da criação, já que ele, assumidamente católico, estaria obrigado pela fé a admitir incontestavelmente o dogma da criação, especialmente depois de Tomás de Aquino haver conseguido concretizar o

* Doutorando do Departamento de Filosofia da USP 
projeto de fundamentação filosófica da creatio ex nihilo, estabelecendo-a como original cosmologia cristã em oposição à cosmologia pagã. O que mais poderia ser a teoria cartesiana senão a ratificação do conteúdo teológico preservado pela ortodoxia cristã? Se a tradição estava correta, isto é, erguida sobre princípios bem fundamentados, não haveria motivo para Descartes retomar o assunto dado por consolidado. Sed contra, Descartes o retomou. Teria ele então notado algo suspeito ou mal fundamentado na cosmologia cristã que serviu como motivo para uma nova teorização da criação?

As investigações que vimos realizando no Doutorado têm encontrado fortes indícios de que as Meditações contêm uma perspectiva cosmológica. Em vista disso, a Primeira Meditação submete à apreciação dubitativa os dois mais importantes sistemas filosóficos existentes à época de Descartes: o realismo e o idealismo. O primeiro fornece as bases para a cosmologia cristã realista; o segundo fundamenta a existência de realidades incriadas e, segundo Descartes, independentes de Deus ${ }^{1}$.

Dada a extensão do assunto, limitar-nos-emos apenas à apreciação dubitativa do realismo e o impacto que ela exerce sobre a cosmologia cristã realista. A inconsistência do realismo ante os ataques da dúvida acarretará sua ruína e, por conseguinte, o desmoronamento da cosmologia cristã sobre ele alicerçada.

\section{Os fundamentos realistas da cosmologia tomasiana}

A cosmologia teve origem na Grécia, precisamente na investigação racional dos primeiros filósofos em torno da physis, rompendo dessa maneira com as cosmogonias própria das narrativas míticas. Toda a cosmologia pagã ${ }^{2}$, de Tales a Porfírio, desenvolveu-se no intuito de consolidar o princípio cosmológico ex nihilo nihil fit, ou seja, que nada procede do nada. Em linhas gerais, o princípio sustenta a eternidade da matéria incriada ou da realidade material existente. Platão e os neoplatônicos acrescentaram as Formas ou Ideias, realidades imateriais, igualmente incriadas. O médio-platonismo, por sua vez, realizou uma operação muito conveniente para o desenvolvimento da filosofia cristã. Ele transformou as Formas ou Ideias platônicas em pensamentos de Deus (Cf. G. Reale e D. Antiseri 6, p. 328-329).

Quando no século II de nossa era aconteceu o encontro do cristianismo com a filosofia, os Padres da Igreja saíram em defesa da fé revelada, afirmando a doutrina da creatio ex nihilo, ou seja, da criação a partir de nada. Afirmada inicialmente como crença identificadora dos cristãos, a creatio ex nihilo foi progressivamente lapidada. Tornou-se doutrina teológica, graças às contribuições patrísticas, especialmente de Agostinho. Mas somente com Tomás de Aquino, no século XIII, a doutrina cristã ganha estatuto filosófico. Fortemente influenciado pelo realismo aristotélico, ele procurará consolidar o projeto de fundamentação filosófica da fé. Ele assegura como racionalmente demonstrável a doutrina teológica da creatio ex nihilo, e declara que "a existência da criação não é algo que se sustenta apenas pela fé, mas que também se demonstra pela razão" (Tomás de Aquino 7, 2sent., d.1, q.1, a.2). Com a demonstração racional da criação, Tomás consolida, em bases realistas, a doutrina teológica como autêntica cosmologia cristã, tendo a creatio ex nihilo como seu princípio cosmológico, em oposição à cosmologia pagã. O legado da Tradição, portanto, compreende duas importantes cosmologias, cada uma com um princípio cosmológico próprio e autêntico: o princípio pagão ex nihilo nihil fit e o cristão creatio ex nihilo.

Seguindo Aristóteles, Tomás admite o princípio de que nada há no intelecto que não tenha passado primeiro pelos sentidos. Nesse princípio se sustenta a gnosiologia realista, que procura explicar como podemos ter um conhecimento universal a partir das coisas sensíveis individuais. É através de um processo gradual chamado abstração (abstractio) que o conhecimento 
universal é formado. Segundo a teoria da abstração, a realidade material existente, composta de coisas sensíveis, deixa suas impressões em nossos sentidos. A imaginação, por sua vez, age sobre os dados fornecidos pelos sentidos, formando assim as espécies sensíveis, também chamadas imagens ou fantasmas, que são representações imateriais de uma realidade material. O intelecto, por sua vez, atuando sobre essas espécies, abstrai delas a quidditas (quididade), isto é, a essência universal, também chamada espécie inteligível, formando, finalmente, um conhecimento verdadeiro. Dessa breve exposição, é importante destacar o seguinte: a existência da realidade material é algo indubitável e indispensável ao conhecimento universal, pois, segundo o realismo, todo conhecimento tem origem na experiência sensível. Por isso, é na realidade sensível que se fundamenta a demonstração tomasiana da criação. Expliquemos, primeiro, os termos da sentença creatio ex nihilo.

\subsection{Explicitação e demonstração tomasiana da creatio ex nihilo}

De acordo com Tomás, "creatio é a produção de uma coisa na sua substância total, sem se pressupor nada de incriado ou de criado por outrem" (Tomás de Aquino 11, I, q. 65, a. 3). Trata-se de um ato que procede diretamente de Deus e exclui qualquer possibilidade de uma matéria preexistente incriada ou de algo criado por outro ser que não seja ele próprio. Por sua vez, a expressão ex nihilo equivale a nenhum ente. Nesse sentido, a preposição ex designaria ordem, "como quando se diz que da manhã (ex mane) se faz o meio-dia, isto é, o meio-dia vem depois da manhã" (Tomás de Aquino 11, I, q. 45, a. 1). Assim, quando se diz que as coisas foram feitas do nada, pretende-se indicar a ordem do que é relativamente ao não-ser precedente. A preposição ex pode também designar a negação da causa material e, nesse sentido, equivale a dizer que "não é feito de alguma coisa" (Idem). Sendo a criação a produção do ser total sem que se possa pressupor algo de criado ou incriado, segue-se que a ação de criar é exclusiva de Deus ${ }^{3}$. Explicados os termos da sentença, orientemo-nos em direção à demonstração racional da creatio ex nihilo construída sobre bases realistas.

O ponto de partida é a existência da realidade material, da qual Tomás inquire se é causada por princípios inerentes à sua própria natureza ou por algum princípio extrínseco. Segundo ele, as coisas materiais não poderiam ser causadas por princípios inerentes à sua própria natureza, uma vez que sua essência não envolve a existência, ou seja, a existência não é essencial para a compreensão de sua quididade:

\begin{abstract}
"Tudo quanto não é essencial a respeito da compreensão da quididade constitui algo que procede de fora e que introduz a composição com a essência, visto que nenhuma essência se pode compreender sem os elementos que constituem partes da essência. Ora, toda essência ou quididade pode ser entendida sem que se compreenda qualquer coisa acerca do seu ser ou de sua existência. Com efeito, posso compreender o que sejam o homem e a fênix, ignorando se possuem ou não existência real. É evidente, por conseguinte que a existência difere da essência ou quididade" (Tomás de Aquino 8, c. 5, 3).
\end{abstract}

Se a existência não decorre da compreensão de sua essência, segue-se que o ser de todas elas é acrescentado de fora. Dessa forma, o ser ou a existência das coisas provém de uma causalidade eficiente e extrínseca. Do contrário, seria preciso sustentar que "uma coisa seria a causa de si mesma, e uma coisa se produziria a si mesma, o que é impossível" (Tomás de Aquino 8, c.5, 4). Portanto, em toda coisa na qual o ser difere da essência, sua existência necessariamente lhe advém 
de outra coisa, que é a sua causa. Por conseguinte, a realidade material é efeito. Entendida como efeito, sua existência é condicionada à existência da causa, pois "o efeito não existe se a causa não existir" (Tomás de Aquino 11, I, q. 44, a.1). Ora, não há dúvida de que o mundo existe. Logo, da existência do mundo, entendido como efeito, é necessário concluir a existência da sua causa, ou seja, Deus. A realidade material, portanto, não é causada por princípios inerentes à sua natureza. Ela requer uma causa que a "faça passar da não-existência para a existência. Ora, tal causa lhe é necessariamente anterior" (Tomás de Aquino 9, c. 6, 9).

Poder-se-ia objetar a Tomás que o percurso argumentativo feito até agora não torna evidente a criação, porque parece ser baseado em pressupostos pouco ou nada evidentes tais como o da distinção entre essência e existência, ou o de que o mundo não possa ser causado por princípios inerentes à sua própria natureza. Em razão disso, Tomás apresenta, na Suma Teológica, as famosas Cinco Vias, com o objetivo de demonstrar a existência de Deus. Elas, no entanto, fornecem para nós as provas da criação fundamentadas nas evidências constatadas pela experiência sensível.

Tomás admite duas espécies de demonstração: uma é a que procede da causa - Deus - em direção aos efeitos - as coisas feitas; a outra parte dos efeitos em direção à sua causa. O Doutor Angélico opta pela segunda, pois os efeitos, como são mais conhecidos por nós, permitem-nos chegar com mais segurança à causa primeira criadora, da qual não temos um conhecimento evidente:

"Há duas espécies de demonstração. Uma, pela causa, pelo porquê das coisas, a qual se apoia simplesmente nas causas primeiras. Outra, pelo efeito, que é chamada a posteriori, embora se baseie no que é primeiro para nós; quando um efeito nos é mais manifesto que a sua causa, por ele chegamos ao conhecimento desta. Ora, podemos demonstrar a existência da causa própria de um efeito, sempre que este nos é mais conhecido que aquela; porque, dependendo os efeitos da causa, a existência deles supõe, necessariamente, a preexistência desta. Por onde, não nos sendo evidente, a existência de Deus é demonstrável pelos efeitos que conhecemos" (Tomás de Aquino 11, I, q. 2, a. 2).

Das Cinco Vias, são as três primeiras que trazem os elementos consideráveis para a demonstração da criação. Analisemos a primeira via que é a do movimento. Os sentidos testemunham e garantem a existência do movimento ${ }^{4}$. Ao se falar em movimento, primeiramente o concebemos como deslocamento espacial. Todavia, movimento significa precisamente a passagem da potência ao ato. "Mover, afirma Tomás, é levar uma coisa da potência ao ato" (Tomás de Aquino 11, I, q. 2, a. 3). No Compêndio de Teologia, ele havia declarado que tudo o que uma vez pode existir e outra vez deixa de existir traz em si a marca da mutabilidade, necessitando de uma causa necessariamente anterior que o faça passar da não-existência à existência. Se mover é levar uma coisa da potência ao ato, esse movimento pressupõe um ser anterior que opere tal mudança naquele que muda. Com efeito, nada pode passar da potência ao ato, do não-ser ao ser por si mesmo, senão por meio de uma causa extrínseca (Tomás de Aquino 9, c. 6-7). Por outro lado, a coisa em mudança não pode estar em potência e ato sob o mesmo aspecto, pois isso viola o princípio de não-contradição. Destarte, “é impossível uma coisa ser motora e movida ou mover-se a si própria" (Tomás de Aquino 11, I, q.2. a.3). Considerando, pois, o princípio de que tudo o que se move é movido por outro, é necessário admitir que o que é movido o seja por outro e assim sucessivamente até se chegar ao primeiro motor, pois os motores segundos não se movem senão pela ação do primeiro, impedindo que o movimento prossiga ao infinito. A passagem 
da potência ao ato só se dá mediante a existência de um ser já em ato. $\mathrm{O}$ movimento do mundo, portanto, remete a uma causa motora primeira.

A admissão da causa motora primeira não nos autoriza afirmar a criação do mundo, pois, como bem nota o próprio Tomás, a criação não pressupõe o movimento ${ }^{5}$. Assim sendo, a primeira via nos autoriza apenas a admitir que o mundo não tem em si mesmo a causa do seu movimento e, consequentemente, não existe por si mesmo, já que carece de uma causa motora extrínseca.

Introduzindo a noção de movimento como passagem da potência ao ato, Tomás valeu-se do princípio de que nada passa da potência ao ato por si mesmo, mas somente por meio de uma causa extrínseca. Para tanto, exige-se um agente em ato, capaz de operar a suposta mudança. A necessidade do agente é que nos insere na segunda via. Nela, partese da análise da natureza da causa eficiente: aquela que, por sua ação, o efeito é produzido.

De acordo com as observações de Tomás, verifica-se nos seres sensíveis certa ordenação das causas eficientes, isto é, em todas elas "a primeira é causa da média e esta da última, sejam as médias muitas ou uma só" (Tomás de Aquino 11, I, q. 2, a. 3). A ordenação das causas eficientes impossibilita que uma coisa seja causa eficiente de si própria, porque isso equivale a dizer que uma coisa é anterior a si mesma, o que não se pode conceber nem é possível assim ser, pois é impossível uma coisa produzir a si mesma, conforme já se observou acima. Poder-se-ia, em contrapartida, aventar a hipótese de a série causal proceder ao infinito. Mas em contrário, Tomás adverte que, considerando a ordem das causas eficientes - a primeira causa da média e esta da última - e considerandose que retirando a causa, o efeito não se produz - pois só existe efeito se a causa existir -, "procedendo ao infinito, não haverá primeira causa, nem efeito último, nem causas eficientes médias, o que evidentemente é falso" (Idem). Donde Tomás conclui a necessária existência de uma causa eficiente absolutamente primeira, que é Deus.

É a introdução da causa eficiente que nos dá uma primeira prova de que o mundo é criado, porque a causalidade eficiente exige a produção de uma coisa por outra anterior. Sendo Deus a causa eficiente primeira é, portanto, a causa produtora do efeito que é o mundo. Portanto, o mundo é criado. A produção do mundo por Deus dispensa a matéria preexistente incriada, conforme já apontamos anteriormente, na explicação dos termos da sentença. Assim, a criação é ex nihilo.

A próxima evidência da criação reside na existência de seres contingentes. A contingência dos seres parece resultar da existência da causa eficiente, que é pressuposta à produção de uma coisa. Como efeito, a contingência é definida por Tomás como poder ser e poder não ser, isto é, como possível, podendo ser gerado e corrompido. Resulta que o contingente não possui em si mesmo a razão de sua existência e, por isso, deve recebê-la de uma causa eficiente anterior. Porque "quod non est, non incipit esse nisi per aliquid quod est"6.

Ora, as coisas sensíveis são testemunhas suficientes da contingência, os sentidos comprovam que coisas nascem e se corrompem, ou seja, vêm a ser e deixam de ser. Se as coisas são possíveis, é impossível terem existido sempre, pois é da natureza do possível não ter sido em algum momento e, portanto, houve algum tempo em que nenhuma delas era, quer dizer, houve um momento em que nada existia. Mas se tudo fosse somente possível, ainda hoje nada existiria, pois algo só passa do não-ser ao ser através de uma causa extrínseca, no caso, um ser em ato, uma coisa já existente ${ }^{7}$.

Visto não serem todos os seres somente possíveis, é forçoso que dentre eles haja algum ser necessário. Quanto a este, Tomás ensina que ou será necessário por si ou em virtude de outro ser necessário. Como de costume, é descartada a possibilidade de regressar ao infinito na série de seres necessários, 
pois, regressando ao infinito, não haveria nenhum ser necessário. Ademais, rigorosamente falando, necessário é aquilo que existe por si e não em virtude de outro. Donde conclui o Aquinate, dizendo que "É forçoso admitir um ser por si necessário, não tendo de fora a causa de sua necessidade, antes, sendo a causa da necessidade dos outros; o que todos chamam Deus" (Idem) ${ }^{8}$. Com esses argumentos, Tomás de Aquino concretiza o projeto de fundamentação filosófica da doutrina da creatio ex nihilo, consolidando-a como autêntica cosmologia cristã sobre as bases do realismo aristotélico.

\section{Descartes e a apreciação dubitativa do realismo}

\subsection{A motivação cartesiana}

Cumpre agora mostrar como Descartes, submetendo o realismo aristotélico-tomista ao método da dúvida, provoca o desmoronamento da cosmologia cristã. O motivo já se apresenta na passagem de abertura da Primeira Meditação:

"Já faz bastante tempo que eu me dei conta de que, desde os meus primeiros anos, eu havia recebido muitas opiniões falsas por verdadeiras, e que o que mais tarde fundei sobre princípios tão mal fundamentados, só poderia ser muito duvidoso e incerto; de modo que era necessário que eu tentasse seriamente, uma vez em minha vida, desfazerme de todas as opiniões nas quais até então acreditara, e começar tudo de novo desde os fundamentos, se eu quisesse estabelecer qualquer coisa firme e constante nas ciências" (Descartes 2, AT IX, p. 13).

Para todo ser humano, a infância é aquele período em que tudo o que se pode saber como verdadeiro se recebe diretamente dos pais emestres, cujas opiniões, por sua vez, alicerçam-se sobre a autoridade dos ensinamentos recebidos dos Antigos e que constituem as verdadeiras opiniões ${ }^{9}$. Transmitilas equivalia a transmitir a verdade, que convenientemente se designa pelo nome de Tradição. Entre os inúmeros ensinamentos recebidos da Tradição, há os da filosofia. "Cultivada pelos mais elevados espíritos que viveram desde muitos séculos, nela não se encontra uma única coisa a respeito da qual não se haja discussão" (Descartes 3, p. 40-41), revelando-se nisto quão pouco firmes eram seus alicerces, de modo que nada sólido poderia ser construído sobre eles (Cf. Idem).

Era de se esperar que Descartes, devido à atitude passiva e infantil frente à Tradição e ao mundo, viesse a fazer o mesmo que fizeram seus pais e mestres, a saber, transmitir a Tradição, fundando sobre os princípios por ela estabelecidos as suas próprias opiniões. Em tempo, porém, percebe haver aceitado como verdadeiras incontáveis opiniões falsas, erguidas sobre princípios mal fundamentados, e "ao considerar quantas opiniões distintas, defendidas por homens eruditos, podem existir acerca de um mesmo assunto, sem que possa haver mais de uma que seja verdadeira, achava quase como falso tudo o que era apenas provável" (Descartes 3, p. 41).

Ao atingir a maturidade suficiente e sair da submissão a seus preceptores, Descartes supera definitivamente a passividade infantil e inicia a execução do propósito há muito concebido de, destruindo os alicerces da Tradição, provocar o inevitável desmoronamento de tudo o que estivesse erguido sobre $\mathrm{el}^{10}$. Começando pelo realismo predominante, Descartes percorre o mesmo caminho da abstractio, cada um dos seus níveis. O menor indício de dúvida encontrado em cada nível constituirá motivo suficiente para o filósofo repelir o realismo, a abstractio e tudo o que sobre ele estiver assentado (Descartes 2, AT IX, 13). 


\subsection{Submissão do fundamento realista ao método da dúvida}

"Tudo o que eu admiti (admisi) até o presente como o mais verdadeiro e seguro, eu aceitei (accepi) dos sentidos ou através dos sentidos: ora, algumas vezes experimentei que esses sentidos eram enganadores, e a prudência recomenda jamais se fiar inteiramente nos que uma vez nos enganaram" (Descartes 2, AT VII, 18) ${ }^{11}$.

Nesse trecho, nitidamente Descartes parafraseia o fundamento do realismo aristotélico-tomista - sobre o qual também se erguera o empirismo de sua época - que diz que nada há no intelecto que não tenha passado pelos sentidos, para logo em seguida lançar uma ponta de dúvida sobre ele. Segundo o trecho, tudo o que se admite como mais verdadeiro e seguro sempre provém dos sentidos, mas de modo diferente. Pode provir diretamente dos sentidos ou mediado por eles, isto é, transformando-se os sentidos em instrumentos pelos quais se extrai o conhecimento verdadeiro.

A realidade exterior é diretamente captada pelos sentidos. Que os sentidos a percebem é algo de que não se pode sensatamente duvidar, pois sua existência lhes é dada independente da vontade humana; as coisas afetam meus sentidos e isso é suficiente para aceitar como verdadeiro que existe a realidade exterior. $\mathrm{O}$ questionamento cartesiano à apreensão direta dos sentidos não representa nenhuma novidade. Este era um ponto comum em toda a tradição filosófica, tanto idealista quanto realista. Os sentidos captam o particular e nesse particular há algo de mutável, de falso. Sendo assim, é incapaz de nos fornecer diretamente um conhecimento verdadeiro e necessário.

Tomás de Aquino, seguindo os passos de Aristóteles, propunha que, para fazer ciência, seria necessário transformar os sentidos em instrumentos. Uma vez que os sentidos não enganam quanto ao perceber a realidade exterior, então não há problema em tomá-los como instrumentos através do qual seja construído o conhecimento verdadeiro, isto quer dizer que os sentidos são instrumentos através dos quais o intelecto extrairá o universal, num processo conhecido por abstractio.

Esse processo, embora rejeite admitir que o conhecimento provém diretamente dos sentidos, jamais previu eliminá-los. A correção estabeleceu sua instrumentalização, preservando-os, assim, como fonte originária de todo conhecimento, conforme estabelecido pela tese de que nada há no intelecto que não tenha passado pelos sentidos. Isso soa como a expressão de uma incondicional confiança neles. Com efeito, a atividade do intelecto consiste apenas em abstrair a espécie inteligível, que lhe é própria, da espécie sensível produzida pelos sentidos sem nada the acrescentar ou retirar.

Descartes reconhece ter admitido e aceitado todas essas posições realistas como verdadeiras e seguras. Ora, se tudo o que é verdadeiro provém direta ou mediatamente dos sentidos, então é verdade que os sentidos não enganam. No entanto, se for possível encontrar alguns poucos casos em que eles nos enganem, seguir-se-á que nem tudo o que é verdadeiro provém deles, quer direta quer mediatamente. Ademais, tal descoberta será suficiente para rejeitá-los e jamais voltar a se fiar ingênua e imprudentemente neles. Entretanto, o fato de algumas vezes os sentidos nos enganarem nos autoriza a concluir que nos enganem sempre? Não estaria Descartes cometendo uma generalização indevida?

Há outra coisa a ser observada. Quando se toma os sentidos como instrumento ou meio, quer-se dizer que alguma coisa através deles atinge outra coisa, isto é, que ele é o meio pelo qual o intelecto conhece a realidade sob a forma inteligível. Sendo assim, diretamente ou através dos sentidos, fato é que o fundamento sobre o qual eles se apoiam é a inquestionável existência da realidade sensível exterior, o substrato indispensável do qual a imaginação, por meio deles, retira os elementos que serão trabalhados pelo intelecto. É impossível duvidar da existência da realidade sensível. 
Com efeito, para o realismo, se não existir realidade exterior, não haverá conhecimento proveniente dos sentidos, nem diretamente nem por seu intermédio e, sendo verdade que nada há no intelecto que não tenha passado pelos sentidos, não haverá conhecimento de modo algum. Logo, não haverá ciência. A existência da realidade sensível, no entanto, é tão evidente ou tão manifesta assim como pretende o realismo? É o que Descartes cuidará de investigar, seguindo o mesmo caminho traçado na abstractio: a realidade afeta os sentidos, com os quais a imaginação produz as imagens sensíveis, sobre as quais o intelecto agindo produz as espécies inteligíveis.

$\mathrm{O}$ fato de os sentidos enganarem algumas vezes não nos autorizaria a rejeitá-los completamente, porque, na maioria das vezes, eles não enganam, como o próprio Descartes observa:

"Se bem que os sentidos às vezes nos enganem no que diz respeito às coisas pouco sensíveis e muito distantes, encontramos talvez muitas outras, das quais não se pode sensatamente duvidar, apesar de as conhecermos por meio deles" (Descartes 2, AT IX, 14).

Ademais, considerando-se as poucas vezes em que enganam, vêse que há uma explicação plausível para isso. É bem provável que nessas poucas vezes, o engano tenha acontecido devido, primeiro, ao objeto ser pouco sensível e, segundo, à sua distância.

Um objeto pouco sensível é por si só inadequado aos sentidos, pois estes são capazes de captar com segurança as coisas sensíveis, excluindo as pouco sensíveis e as imateriais. Considerando os objetos pouco sensíveis de um lado e os sentidos do outro, o que se pode notar é que os próprios objetos pouco sensíveis estariam enganando os sentidos, porque não possuem sensibilidade suficiente.
Depois, um objeto muito distante comprometeria igualmente a percepção sensível. Com efeito, em razão da distância mesma, a experiência sensível é prejudicada, pois o objeto não fica suficientemente perceptível. A percepção de um objeto pelos sentidos exige dele completa sensibilidade e total proximidade. Satisfeitas essas condições, os sentidos garantem uma percepção inequívoca do seu objeto. Aparentemente de acordo, Descartes enumera algumas coisas tão próximas quanto sensíveis das quais seria insensato duvidar de que são conhecidas através dos sentidos: estar em um lugar físico, cercado de objetos com os quais seu corpo e suas mãos interagem. Em condições tão privilegiadas como estas, só mesmo sob efeito da loucura para se ter uma percepção que não corresponda à realidade ${ }^{12}$.

Assim como se exige dos objetos satisfazerem as condições de completa sensibilidade e total proximidade, exige-se que o sujeito esteja em condições normais para não comprometer a percepção sensível, ou seja, o sujeito deve estar no mais perfeito funcionamento de sua capacidade mental, isto é, sem o menor defeito no seu bom senso. Existindo tais condições, tanto para o objeto quanto para o sujeito, os sentidos têm, portanto, total autoridade para fornecer do modo mais verdadeiro e seguro o conhecimento verdadeiro através dos sentidos.

\subsection{O argumento do sonho e a invalidação dos sentidos}

Só então Descartes traz à tona o argumento do sonho, por meio do qual, preservando todas as condições até aqui exigidas, submete-as ao método da dúvida, a fim de verificar até onde os sentidos conseguirão resistir. Antes, porém, Descartes faz algumas observações.

A primeira consiste em considerar o ato de dormir e sonhar como hábitos normais do homem. Tal observação atenta para as condições normais nas quais deve estar o sujeito, ou seja, o sonho, por mais extravagante que seja, 
ao ponto de se assemelhar às coisas representadas pelos dementes despertos, nem por isso significa um mau funcionamento da sensação do sujeito ou defeito no seu bom senso. A extravagância onírica ou sua discrepância com a realidade é indício suficiente de que é sonho e que, portanto, a sensação não me engana. O sonho extravagante, porém, é uma situação atípica ${ }^{13}$.

Seria possível a sensação perceber nitidamente a distinção entre vigília e sonho? Não seria apenas o hábito aliado a certas condições exteriores percebidas pelos sentidos - como o costume de dormir à noite, quando temos a sensação de sonolência - o princípio da certeza de que se distingue de modo inconfundível a realidade do sonho? ${ }^{14}$ Para saber se a sensação, no seu perfeito funcionamento é capaz de distinguir a vigília do sono, garantindo assim que aquilo que percebe é efetivamente a realidade e não pura ilusão, Descartes evoca outra situação mais típica e mais provável:

"Afigura-se-me agora que não é com olhos adormecidos que olho para este papel; que esta cabeça que eu movo não se encontra adormecida; que é com intento deliberado que estendo esta mão e que a sinto: o que sucede no sono não parece ser tão claro nem tão distinto quanto tudo isso. Porém, meditando diligentemente sobre isso, recordo-me de haver sido muitas vezes enganado, quando dormia, por ilusões análogas" (Descartes 2, AT IX, 14-15).

Na presente situação, em que Descartes garante estar completamente desperto, consciente e atento a todas as suas ações e sensações, decidindo cada uma delas, ele reconhece suceder o mesmo em certos sonhos, nos quais estava tão desperto e consciente de si, de suas ações e sensações quanto agora. As experiências do agora são de tal maneira idênticas àquelas experimentadas no sonho que se torna impossível distinguir claramente se o agora é sonho ou se é realidade.
Esse trecho submete simultaneamente à dúvida as condições exigidas dos objetos e aquelas exigidas do sujeito. A respeito dos objetos, agora como no sonho, eles satisfazem as condições de proximidade e completa sensibilidade. No sonho, os sentidos têm a mesma sensação inequívoca dos objetos. Quanto ao sujeito, sua percepção sensível encontrase no seu mais perfeito funcionamento, quer dizer que a percepção de estar desperto, consciente e atento a todas as ações e sensações ocorre de modo inconfundível, tanto que Descartes ressalta que estende a mão e que a sente. É necessário que no sonho como agora tais condições sejam preservadas, a fim de que os sentidos, operando perfeitamente, produzam no sujeito um conhecimento verdadeiro.

No entanto, o recurso ao argumento do sonho mostra que o cumprimento dessas exigências não garante o resultado esperado, ou seja, o conhecimento verdadeiro por parte dos sentidos que possa garantir com tamanha clareza e distinção que a percepção das coisas conhecidas através deles seja uma percepção correspondente a coisas realmente existentes e não a ilusões. De fato, os sentidos se mostram incapazes de garantir que aquilo que percebem corresponde ao que existe efetivamente, pois, no sonho, acontece de se ter uma experiência sensível muito real do que não é real ${ }^{15}$. Descartes, porém, ressalta que no sonho como agora, ninguém pode negar que a percepção existe, quer dizer, que os sentidos percebem a existência de uma realidade exterior que os afeta (Cf. Forlin 4, p. 60-61). E ainda acrescenta:

"É necessário ao menos confessar que as coisas que nos são representadas durante o sono são como quadros e pinturas, que só podem ser formados à semelhança de alguma coisa real e verdadeira; e que, ao menos dessa maneira, essas coisas gerais, isto é, olhos, cabeça, mãos e todo o resto do corpo, não são coisas imaginárias, e sim verdadeiras e existentes" (Descartes 2, AT IX, 15). 
Quando sonhamos, representamos no mais das vezes as mesmas coisas com as quais lidamos quando despertos. Do mesmo modo, no processo de abstração, a imaginação retém as imagens que são semelhantes àquilo que os sentidos captam. Quer sonhando, quer desperto, toda representação sensível tem um fundamento real, isto é, toda representação é representação de alguma coisa verdadeiramente existente. Agora, Descartes pretende atacar o segundo nível da abstractio, quando a imaginação contém em si as imagens sensíveis dos objetos captados pelos sentidos.

Em linhas gerais, de acordo com o realismo, a imaginação, por meio dos sentidos externos, produz o fantasma, com o qual as coisas sensíveis se assemelham e sobre o qual o intelecto agirá para produzir as espécies inteligíveis, formando os universais. "Seu fundamento real consiste em que sua formação por meio do intelecto dependa, ao menos parcialmente, das coisas sensíveis" Guerrero 5, p. 90). Todavia, se o universal, adquirido a partir das coisas sensíveis, decorre da abstração operada sobre o fantasma, deve-se assumir, a fim de que a relação entre intelecto e fantasma seja suficiente para dar fundamento real ao universal no que concerne à sua origem, que o fantasma é sempre uma semelhança de coisas sensíveis realmente existentes (Cf. Idem, p. 90-91). Ao que Descartes alude, dizendo que são como quadros e pinturas, que só são formados à semelhança de alguma coisa real e verdadeira. Assim, para existir representação é necessário existir alguma coisa real, ou seja, toda representação tem fundamento real, que são as coisas verdadeiras e existentes e não imaginárias. Ora, se nada provém do nada, a representação só poderá provir de coisas reais e não imaginárias, pois a representação pressupõe a coisa verdadeiramente existente que será representada. Com efeito, nada há no intelecto que não tenha passado pelos sentidos. Prova disso são os pintores que, mesmo representando quimeras por formas estranhas e excepcionais, são incapazes de lhes conferir formas e naturezas totalmente novas, antes fazem certa mistura e composição dos membros dos animais já vistos (Cf. Descartes 2, AT IX, 15). Descartes diz mais:

"se por acaso sua imaginação [a dos pintores] for suficientemente extravagante para criar algo tão novo, que nunca tenhamos visto, e que desta forma sua obra nos represente uma coisa puramente fictícia e absolutamente falsa, com certeza ao menos as cores com que eles a executam devem ser verdadeiras" (Descartes 2, AT IX, 15).

Ora, se toda representação é representação de alguma coisa, nossas representações todas, mesmo as fictícias e falsas pressupõem algo verdadeiro a partir do qual se configure a representação. Como já dissemos, o fundamento de toda representação se encontra nas coisas verdadeiras e existentes, ou seja, toda representação tem fundamento real. Qualquer representação que parta de outra coisa que não sejam essas é por si só fictícia e absolutamente falsa. Se agora parece que Descartes assume essa tese para si, o que ele pretende de fato é submetê-la à dúvida.

Antes, porém, cumpre observarmos que, para a teoria da abstração, a imaginação produz o fantasma ao combinar e unificar as espécies sensíveis. A imagem, por exemplo, de uma cadeira é produzida através da combinação e unificação das espécies sensíveis relativas à grandeza, aspereza, cor, profundidade "de maneira que, nesse fantasma, diversas semelhanças recebidas nos sentidos estarão presentes sob a forma de uma semelhança intrinsecamente individual de algo que pode ser dado aos sentidos" (Guerrero 5, p. 91). Não cabe à imaginação criar as determinações sensíveis que compõem o fantasma; ela apenas utiliza essas determinações dadas nos sentidos. Acontece que a natureza ativa da imaginação é uma atividade interna da alma e, como tal, a imaginação tanto poderá formar imagens semelhantes às coisas sensíveis existentes fora da alma como poderá formar imagens que 
não correspondem a algo realmente existente. Sendo assim, não parece haver garantia de que as espécies inteligíveis produzidas pelo intelecto tenham fundamento real, isto é, que se originem nas coisas sensíveis existentes por serem abstraídas do fantasma e não em ficções. Que fundamento real essas imagens subjetivas, que algumas vezes são formadas de modo totalmente arbitrário pela imaginação, são capazes de dar às espécies inteligíveis que delas são abstraídas? Não há, infelizmente, qualquer garantia de que as espécies inteligíveis se assemelhem efetivamente às naturezas corpóreas existentes na natureza. Desta maneira, as coisas gerais de que fala Descartes podem muito bem ser todas imaginárias.

\subsection{Descoberta das coisas simples e universais e rejeição do realismo}

O trecho seguinte parece supor e admitir toda essa explanação realista, para logo em seguida fazer uma importante ressalva:

"Mesmo que estas coisas gerais, isto é, olhos, cabeça, mãos e outras análogas, possam ser imaginárias, é necessário confessar que existem outras bem mais simples e universais, que são verdadeiras e existentes, de cuja mistura, nem mais nem menos que da mistura de algumas cores verdadeiras, são formadas todas essas imagens das coisas que se situam em nosso pensamento, quer verdadeiras e reais, quer fictícias e fantásticas. Desse gênero de coisas é a natureza corpórea em geral, e sua extensão; juntamente com a figura das coisas extensas, sua quantidade, ou grandeza, e seu número; como também o lugar em que se encontram, o tempo que mede sua duração e outras coisas análogas" (Descartes 2, AT IX, 15).

Com a descoberta das coisas simples e universais, Descartes parece chegar ao último nível da abstractio, para rejeitá-la definitivamente. Tudo o que ele descreve aqui já era observado por Tomás. Vejamos como isso ocorre.

De que as coisas gerais possam ser imaginárias não se segue que tudo seja fictício. Com efeito, além das coisas gerais, há as coisas simples e universais, consideradas verdadeiras e existentes, de cuja mistura, afirma Descartes, são formadas as imagens das coisas que se situam em nosso pensamento, sejam verdadeiras e reais, sejam fictícias e fantásticas.

Assim como os partidários da abstractio, Descartes encontra-se acima da imaginação, a saber, no interior do intelecto onde se encontram, segundo eles, as espécies inteligíveis. A menção cartesiana às "imagens no pensamento" e não mais na imaginação nos leva a crer que se trata das espécies inteligíveis e não das espécies sensíveis, localizadas na imaginação. Assim, as imagens no pensamento podem muito bem corresponder às espécies inteligíveis, à quidditas ou essência universal abstraída pelo intelecto.

Forlin, tratando do debate entre os estudiosos Martial Gueroult e Harry G. Frankfurt em torno das coisas simples e universais, mostra que "consideradas elementos constitutivos do mundo de coisas extensas tanto podem ser consideradas meras condições necessárias de toda representação possível (no caso de não haver mundo material exterior) - tal é interpretação feita por Gueroult-quanto condições necessárias de toda coisa extensa possível (no caso da existência de um mundo material exterior) - que é a interpretação de Frankfurt" (Forlin 4, p. 70) ${ }^{16}$. Forlin lembra que, como noções da mente, elas são propriedades essenciais das coisas extensas, independente do estatuto do mundo, tenha ele ou não existência exterior à mente. Dessa maneira, o que se deve afirmar "é que as coisas simples e universais são condições necessárias de todas as coisas extensas, sejam elas meras representações minhas ou coisas materiais exteriores a mim" (Idem). À mesma ponderação já chegavam os teóricos da abstractio, mas tomavam-na como um problema. 
Segundo os teóricos da abstração, é certo afirmar que, ao operar sobre os fantasmas, o intelecto produz as espécies inteligíveis. Mas isso não quer dizer que as espécies inteligíveis sejam semelhanças de coisas reais. Conforme explica Guerrero, "a posse de um conceito não implica a instanciação do mesmo, uma vez que a operação de intelecção não visa ao ser das coisas, mas às suas determinações formais" (Guerrero 5, p. 92) e, assim, o fundamento real não consistiria apenas na produção de semelhanças. Quando a imaginação produz o fantasma, ela nada lhe acrescenta que já não estivesse presente, isoladamente, nas espécies sensíveis. Assim, do fato de as espécies inteligíveis serem extraídas dos fantasmas, garante-se que, a princípio, não haverá nada no conteúdo da espécie que não seja uma determinação possível de um objeto sensível. Guerrero conclui, dizendo:

“Ainda que as determinações inteligidas não se encontrem em nenhum objeto real, ao menos seria possivel, em princípio, que elas estivessem concretizadas em sujeitos individuais [...] Em outras palavras, o fundamento real do universal, que decorre de o processo abstrativo darse por meio de uma certa relação entre intelecto agente e fantasmas, consiste em que o resultado desse processo seja efetivamente a semelhança de uma natureza corpórea, quer ela exista, quer não exista" (Guerrero 5, p. 91).

Ora, atento a essa questão, Tomás, no século XIII, visava justamente encontrar uma solução satisfatória. Sua teoria abstracionista pretendia explicar "como os universais, existindo apenas na alma e sendo produtos de uma atividade sua, poderiam ainda assim ter algum fundamento real, ou seja, por que não se deveria considerá-los meros produtos ou caprichos da alma" (Idem, p. 70).

Sendo assim, Descartes e os partidários da abstractio chegam ao mesmo ponto, isto é, àquelas coisas tomadas como condição necessária de todas as coisas extensas, quer sejam meras representações, quer sejam coisas materiais exteriores. Os abstracionistas, apesar do caráter duvidoso da teoria, resolvem o problema insistindo no aprimoramento e preservação do fundamento real da abstractio, ou seja, em que as espécies inteligíveis são formadas a partir da realidade exterior mediante os sentidos. Descartes, ao contrário, não pode nem vai permanecer nesse espaço conceitual realista. Para ele, em razão da resistência das coisas simples e universais à dúvida natural, não há nada nelas que nos permita considerá-las duvidosas ou suspeitas de falsidade. Por isso, são verdadeiras e existentes. Duvidoso é o fundamento real da abstractio que a elas conduz, a saber, que elas têm origem numa realidade exterior existente que se dá ao intelecto através dos sentidos.

É precisamente a isso que Descartes se opõe. Com efeito, se o fundamento é duvidoso, se o que os sentidos captam não aparece clara e distintamente como o verdadeiramente existente, torna-se impossível conhecer com verdade as coisas simples e universais a partir deles. Aliás, Descartes assinala que as ciências que dependem das coisas compostas manifestam-se dúbias e incertas ${ }^{17}$. Coerente com o método adotado e ante os indícios de dúvida encontrados, era necessário rejeitar todo o aparato teórico realista, que, nas palavras de Descartes, assenta-se na tese segundo a qual tudo o que se admite como verdadeiro e certo advém dos sentidos ou através dos sentidos. Como da destruição do fundamento, provoca-se o desmoronamento de todo o edifício erguido sobre ele, há um impacto direto sobre a cosmologia cristã.

\section{Impacto sobre a cosmologia cristã}

Se agora considerarmos a teoria da criação cristã, cuja forma definitiva e ortodoxa foi dada por Tomás, como uma daquelas antigas opiniões às quais Descartes confessara ter dado crédito, e que a presente 
teoria foi erguida sobre o fundamento do realismo aristotélico-tomista, percebemos que sua exposição ao método da dúvida a revela estabelecida sobre princípios tão mal fundamentados que só pode ser duvidosa e incerta. Não se pretende nem é necessário repetir a argumentação tomasiana, mas somente fazer uma breve recapitulação, para que, à luz da crítica cartesiana, vejamos como ocorre a destruição dos seus argumentos mais fundamentais.

Conforme já relatamos, segundo Tomás, a realidade material existe e é conhecida de maneira evidente. Essa realidade tem origem em uma causa eficiente, a menos que se queira sustentar o absurdo de algo ser capaz de produzir a si mesmo, sendo anterior a si mesmo, contrariando, assim, a própria experiência sensível. Porque causada, a realidade material é efeito. Sendo assim, recebe o seu ser de uma causa externa e, consequentemente, sua essência não envolve a existência. Ora, se é evidente que a realidade existente é efeito de uma causa, Tomás então considera como a melhor maneira de conhecer essa causa partindo do efeito, ou seja, a posteriori, pois o efeito é o que se dá primeiro e é mais manifesto para nós do que a causa, à qual chegamos por seu intermédio. Assim, na análise do efeito, que é a realidade material, encontram-se os elementos necessários à demonstração de sua criação e da existência de Deus. A realidade material, portanto, dáse diretamente aos sentidos, os quais, querendo ou não, são afetados por ela constantemente, pois ela é o que há de primeiro e mais manifesto. Por meio da abstração, ou seja, através dos sentidos sobre os quais age a imaginação, o intelecto é capaz de produzir um conhecimento verdadeiro acerca da realidade exterior, cuja evidente insuficiência ontológica atestada pelos sentidos leva à demonstração racional de sua criação e do seu Criador.

Entretanto, na Primeira Meditação - até à descoberta das coisas simples e universais -, a execução do método da dúvida destrói o fundamento real da abstractio. A realidade sensível, cuja existência é captada diretamente pelos sentidos - através dos quais é produzido pelo intelecto um conhecimento sistemático acerca do que é sensível e do que não é sensível - pode ser uma ilusão e não existir, correspondendo a uma ficção produzida pela imaginação. Isto significa que não existe nenhuma prova definitiva da existência da realidade sensível exterior. Sendo assim, como fundamentar a origem das coisas simples e universais nas coisas sensíveis, se não há evidência segura de que estas existam ou que sejam tais como os sentidos as percebem? Em razão disso, a existência de uma realidade sensível exterior evidencia-se, na verdade, como um pressuposto ou postulado.

A descoberta de que os sentidos são falazes impugna qualquer possibilidade de demonstração baseada neles. Logo, se não é possível saber que o mundo existe, menos ainda que ele seja efeito de uma causa divina. Nesse estado de coisas, o mundo pode ser efeito de minha imaginação, ou de um Deus enganador, ou obra do destino, da fatalidade ou do acaso, ou ainda de um gênio maligno (Cf. Descartes 2, AT IX, 16-18).

Todos os elementos demonstrativos da existência de Deus e da criação nos quais se baseiam as Cinco Vias perdem a eficácia, porque partem de uma coisa tomada como existente, mas que pode não existir, ou seja, partem do pressuposto de que a realidade sensível exterior existe, quando, na verdade, mantidos os fundamentos realistas, nada garante a existência da realidade sensível, nem que seja efeito nem que sua causa seja Deus. Todos os fenômenos constatados pelos sentidos e transformados em provas da existência de Deus e da criação podem ser meras conexões arbitrárias da imaginação. Uma vez que não é possível ter certeza da existência da realidade exterior nem de que ela seja tal como a conhecemos, tanto se tornam inválidas as provas da existência de Deus como as da criação.

A cosmologia cristã consolidada por Tomás, portanto, evidenciase alicerçada sobre um frágil fundamento: o pressuposto da incontestável existência da realidade exterior, o qual, aliás, parece gozar de estatuto 
superior de existência que o próprio Deus, ou seja, a realidade exterior é algo evidente, enquanto a existência de Deus, causa criadora do mundo, carece de evidência. Além disso, a existência de Deus, o supremo fundamento, parece apoiar-se em algo desprovido de fundamento.

Se a existência de Deus necessita de provas, o mundo necessita ainda mais. Assim, os princípios fundamentais da prova tomasiana mostram-se frágeis e suas demonstrações sem efeito. Se não há nenhuma garantia segura quanto à existência do mundo, não se pode proceder causalmente à existência de Deus. Ante a possibilidade de o mundo ser uma ilusão ou ficção da imaginação, nada impede que o Deus postulado causa deste mundo ilusório seja, também ele, uma fábula. Dessa maneira, malgrado todos os esforços empreendidos por Tomás para demonstrar racionalmente a doutrina da creatio ex nihilo, através de que se consolida uma nova cosmologia em lugar da cosmologia pagã, o que se vê de fato com a apreciação dubitativa do realismo aristotélico-tomista é o contrário: não demonstra a existência de Deus nem a da criação. Primeiro, porque pressupõe a existência do mundo como algo evidente. Em segundo lugar, uma vez que a existência do mundo não é evidente, deveria ser feita sua demonstração. E mesmo fazendo a demonstração da existência do mundo, ela não é suficiente para demonstrar a existência de Deus. Tomás, no entanto, acertou quanto ao seguinte: a criação pode ser demonstrada filosoficamente, desafiadora tarefa que o próprio Descartes cuidará de executar, inaugurando assim a cosmologia moderna.

\section{DUBITATIVE APPRECIATION OF THE REALISM AND ITS IMPACT ON THE REALISTIC CHRISTIAN COSMOLOGY}

Abstract: This article wants to expose the dubitative appreciation of realism in the First Meditation, in order to show the impact of this Cartesian action on the doctrine of creation ex nihilo, philosophically consolidated as authentic Christian cosmology by Aquinas, in substitution to the pagan cosmology built upon the principle ex nihilo nihil fit. First, we will make a brief statement of the realistic foundations that give support to the proofs of the creation developed by Aquinas. Then we will present how the submission of realism to the Cartesian method of doubt entails the inevitable collapse of the cosmological Christian building.

Keywords: Thomas Aquinas. Realism. Cosmology. Descartes. Doubt.

\section{REFERÊNCIAS BIBLIOGRÁFICAS:}

1. AUBENQUE, P.; BERnHARDT, J.; CHÂTELET, F. A Filosofia Pagã: do séc. IV a.C ao séc. III d.C. Coleção História da Filosofia, n. 1. Tradução de Maria Helena Couto Lopes e Nina Constante Pereira. Lisboa: Publicações Dom Quixote, 1983.

2. DESCARTES, R. Oeuvres de Descartes. Ed. de C. Adam e P. Tannery. 11 vols. Paris: Vrin, 1996.

3. . Discurso do Método. Tradução de Enrico Corvisieri. Coleção Os Pensadores, São Paulo: Nova Cultural, 2004.

4. FORLIN, E. A Teoria Cartesiana da Verdade. São Paulo: Humanitas/Unijuí, 2005.

5. GUERRERO, M. K. O Processo de Abstração e o Fundamento Real dos Universais em Tomás de Aquino. In Revista Indice, vol. 1, n. 1. Rio de Janeiro: 2009.

6. REALE, G. \& ANTISERI, D. História da Filosofia I: Antiguidade e Idade Média. São Paulo: Paulus, 1990.

7. TOMÁS DE AQUINO. Scriptum super Sententiis.

8.

. Compendium Theologiae.

10._. Summa contra Gentiles. (As obras tomasianas compreendidas entre as referências 7 e 10 foram extraídas da Opera Omnia, disponível no endereço eletrônico http://www.corpusthomisticum.org/iopera.html). Acessadas em 30/05/2012.

11. Suma Teológica. Tradução coordenada por Carlos- Josaphat de Oliveira. São Paulo: Loyola, 2001.

12. Questões Discutidas sobre a verdade (Questão I). T T r a d u çã o de Luiz João Baraúna. Coleção Os Pensadores. São Paulo: Nova Cultural, 2004 


\section{NOTAS:}

1. A problemática acerca da existência de realidades incriadas e independentes de Deus é analisada pela teoria cartesiana da livre criação das verdades eternas, desenvolvida por Descartes entre os anos 1630-1649. A passagem a seguir foi extraída da carta de 15 de abril de 1630, e nos dá uma ideia precisa da necessidade da criação das verdades eternas, entre as quais as verdades matemáticas, que são abordadas na Primeira Meditação, quando são introduzidas as coisas simples e universais: “As verdades matemáticas, que vós nomeais eternas, foram estabelecidas por Deus e dele dependem inteiramente, assim como o resto das criaturas. É, com efeito, falar de Deus como de um Júpiter ou Saturno, e o sujeitar ao Estíge e aos Destinos, dizer que essas verdades são independentes dele. Não temais, eu vos peço, assegurar e publicar que foi Deus quem estabeleceu essas leis na natureza, tal qual um rei estabelece leis em seu reino" (Descartes 2, AT I, 145.)

2. A expressão filosofia Pagã foi utilizada pelos autores P. Aubenque, J. Bernhardt e F. Châtelet, como forma de homenagear Alexandre Kojève. Segundo os autores, a história da filosofia pagã compreende o período que do surgimento da Filosofia com Tales de Mileto até Porfírio, editor de Plotino, cujos textos pertencem ao século III de nossa era. (Cf. AUBENQUE, P.; BERNHARDT, J.; CHÂTELET, F. 1, p. 15).

3. "Criar não pode ser ação própria senão de Deus somente. Pois, é necessário que os efeitos mais universais sejam reduzidos a causas mais universais e primeiras. Ora, dentre todos os efeitos, o mais universal é o ser em si mesmo. Por onde, importa seja ele o efeito próprio da causa primeira e universalíssima que é Deus. E por isso também se diz que nem a inteligência nem a alma nobre dá o ser senão enquanto opera por operação divina. Porém, produzir o ser em absoluto, e não enquanto tal ou tal, pertence à noção de criação. Por onde é manifesto que a criação é ação peculiar do próprio Deus" (Tomás de Aquino 11, I, q. 45, a. 5).

4. "A primeira via e a mais manifesta é a procedente do movimento; pois é certo e verificado pelos sentidos, que alguns seres são movidos neste mundo" (Tomás de Aquino 11, I, q. 2, a. 3).

5. "Embora o universo tenha começado a existir depois de não ter existido, não é necessário que tal tenha ocorrido através de uma mudança, mas sim mediante criação. Esta não constitui mudança no sentido próprio do termo, senão que constitui uma relação da coisa criada, dependente do Criador no seu ser. Para que haja uma verdadeira mudança, é preciso um algo que uma vez é isto e depois passa a ser aquilo. Ora, tal não ocorre no caso de uma verdadeira criação" (Tomás de Aquino 9, c. 99, 190).

6. "o que não é, só pode começar a existir por meio de uma coisa já existente" (Tomás de Aquino 11, I, q. 2, a. 3).

7. "Se tal fosse verdade, ainda agora nada existiria, pois o que não é só pode começar a existir por uma coisa já existente; ora, nenhum ente existindo, é impossivel que algum comece a existir e, portanto, nada existiria, o que, evidentemente, é falso" (Tomás de Aquino 11, I q. 2, a. 3).

8. As vias seguintes não trarão nenhuma prova da criação e, por isso, decidimos não nos deter em sua análise. Não obstante, elas dão consideráveis descrições da criação e do seu Criador. A contingência da criação não a torna insignificante. Pelo contrário, nos seres contingentes é possível encontrar a perfeição distribuída em graus, que vão do mínimo aos mais elevados. De fato, há seres mais e menos perfeitos do que outros. Ora, se há a perfeição em seu grau mínimo, deve haver, e há "algo verdadeiríssimo, ótimo e nobilíssimo e, por conseguinte, maximamente ser" (Idem), que é a causa da perfeição encontrada nos demais seres. Se a criação goza gradualmente da perfeição daquele que é maximamente ser e, por isso, perfeitíssimo, então não procede pensar que o universo seja mau, caótico ou proveniente do caos. Como mostrará a quinta via, observando a ordenação dos seres, especialmente naqueles que não possuem conhecimento, pode-se notar que todos concorrem a um fim. Com efeito, "é impossível que coisas contrárias e dissonantes estejam sempre, ou muitas vezes, concordes em uma só ordem, a não ser que estejam também sob o governo de alguém pelo qual é dado a todas e a cada uma dirigirem-se a determinado fim" (Tomás de Aquino 10, I, 13, 27). Assim, a existência da ordenação, de lei ou regularidade encontrada na natureza exige uma intenção, a qual, por conseguinte, pressupõe um ente inteligente. A causa eficiente do mundo, portanto, é um ser perfeito e inteligente e bom. Consequentemente, o efeito, que é a criação, não é mau nem fruto do acaso.

9. "Fui instruido nas letras desde a infância, e por me haver convencido de que, por intermédio delas, poder-se-ia adquirir um conhecimento claro e seguro de tudo o que é útil à vida, sentia extraordinário desejo de aprendê-las" (Descartes 3, p. 37).

10. "E acreditei com firmeza em que, por este meio, conseguiria conduzir minha vida muito melhor do que se a construisse apenas sobre principios a respeito dos quais me deixara convencer em minha juventude, sem ter nunca analisado se eram verdadeiros" (Descartes 3, p. 45). 
11. A apreciação dubitativa do realismo começa nesse trecho citado, quando Descartes parafraseia o princípio realista, e se encerra com a descoberta das coisas simples e universais, a partir da qual tem início a apreciação dubitativa do idealismo, que decidimos não abordar aqui, esperando fazê-lo em outra oportunidade.

12. "Exceto, talvez, que eu me compare a esses dementes, cujo cérebro está de tal maneira perturbado pela e ofuscado pelos negros vapores da bile que amiúde garantem que são reis, enquanto são bastante pobres; que estão trajados de ouro e púrpura, enquanto estão totalmente nus; ou imaginam ser vasos ou possuir um corpo de vidro. São loucos e eu não seria menos excêntrico se me pautasse por seus exemplos" (Descartes 2, AT IX, 14).

13. Por exemplo, em alguns sonhos extravagantes, ocorre de a fisionomia de uma pessoa repentinamente assumir a de outra. Ora, como tal coisa é impossível na realidade, logo se percebe muito claramente que se trata de um sonho.

14. "Contudo, devo aqui ponderar que sou homem, e, consequentemente, que tenho o hábito de dormir e de representar, em meus sonhos, as mesmas coisas, ou algumas vezes menos prováveis, que esses dementes despertos. Quantas vezes me aconteceu sonhar, durante a noite, que me encontrava neste lugar, vestido e próximo do fogo, apesar de me achar totalmente nu em minha cama?" (Descartes 2, AT IX, 14-15).

15. Tomás de Aquino, aliás, já aludia, no século XIII, ao engano dos sentidos. Seguindo Agostinho, ele afirma que o problema dos sentidos é que só percebem o que é mutável e, como a verdade é imutável, não pode ser percebida por eles. Em razão do seu caráter mutável, não existe nenhuma coisa sensível que não encerre algo que se assemelha ao falso, de maneira que não é possível discernir. Diz ele: "Tudo quanto apreendemos através dos sentidos corporais, também quando as coisas não estão presentes aos sentidos, recebemos as imagens dessas coisas como se nos estivessem presentes, tal como acontece também no sono ou em acessos de furor. Ora, a verdade nada encerra em si que se assemelhe ao falso, logo não pode ser apreendida pelos sentidos" (Tomás de Aquino 12, q. I, a. 4). Portanto, Tomás e Descartes concordam que, na atividade onírica, experimentamos os objetos tão presentes, próximos e tão sensíveis que não é possível discernir se eles são ou não reais.

16. Para uma análise mais detalhada acerca do debate entre Martial Gueroult e Harry

G. Frankfurt em torno das coisas simples e universais, veja-se Forlin, 4, p. 57-81.

17. "Talvez seja por isso que nós não concluamos mal se afirmarmos que a física, a astronomia, a medicina e todas as outras ciências dependentes da consideração das coisas compostas são muito dúbias e incertas". (Descartes 2, AT IX, 16).

\section{A ÉTICA DOS ESTOICOS ANTIGOS E O ESTEREÓTIPO ESTOICO NA MODERNIDADE*}

Drayfine Teixeira Moura

Resumo: Tendo em vista que o estoicismo é a corrente helenística que mais influenciou a Filosofia ocidental, a intenção deste artigo é apresentar e esclarecer alguns dos mais comuns estereótipos que a modernidade cunhou acerca da teoria estoica. Para tanto, fazemos uma apresentação dos principais aspectos da ética estoica e analisamos alguns conceitos que, mais tarde, serão os principais alvos de crítica à escola do pórtico. Acusada de ser uma corrente filosófica que prega o comodismo, a aniquilação dos sentimentos e o domínio absoluto da razão sobre as paixões, o estoicismo é muitas vezes mal interpretado por seus opositores. Comentamos também neste texto a crítica feita por Spinoza no prefácio do quinto livro da Ética, cuja ênfase em conceitos como "experiência" e "vontade" ajuda a esclarecer como o estoicismo é encarado na modernidade.

Palavras-chave: Ética, Ética estoica, Estoicismo romano, Estoicismo na Filosofia moderna, Estoicos e Spinoza.

\section{A teoria ética dos primeiros estóicos}

O estoicismo é uma escola helenística fundada por Zenão de Cício ao final do séc. II a.C e cuja influência se estende desde a Grécia antiga até filosofias recentes do sec. XIX, como podemos encontrar nos estudos contemporâneos que sondam as influências estoicas em Kant e Freud. ${ }^{1}$

A escola estoica defendia uma doutrina una e coerente e muitas vezes representavam sua doutrina pela imagem de uma árvore (onde o caule seria a física, os galhos, a lógica; e as folhas seriam a ética, ou moral);

*Artigo produzido durante Iniciação Científica financiada pela bolsa PRP/Santader/FFLCH 